\title{
Extraction, Preliminary Characterization and Evaluation of in Vitro Antitumor and Antioxidant Activities of Polysaccharides from Mentha piperita
}

\section{Xin Liu ${ }^{1, \dagger}$, Zhen-Liang Sun ${ }^{2, \dagger}$, Ai-Rong Jia ${ }^{1}$, Ya-Ping Shi ${ }^{1}$, Rui-Hong Li ${ }^{3, *}$ and Pei-Ming Yang ${ }^{2, *}$}

1 Biology Institute of Shandong Academy of Sciences/Key Laboratory for Applied Microbiology of Shandong Province, Jinan 250014, China; E-Mails: rock0515@163.com (X.L.); jiaar@sdas.org (A.-R.J.); hand-user@163.com (Y.-P.S.)

2 State Key Laboratory of New Drug \& Pharmaceutical Process, Shanghai Institute of Pharmaceutical Industry, Shanghai 200040, China;

E-Mail: hope1126@hotmail.com

3 Fengxian Hospital Affiliated to Southern Medical University, 6600 NanFeng Road, Shanghai 201499, China

$\dagger$ These authors contributed equally to this work.

* Authors to whom correspondence should be addressed;

E-Mails: fengxianhospital@163.com (R.-H.L.); peimingy@163.com (P.-M.Y.);

Tel./Fax: +86-21-5742-3899 (R.-H. L.); +86-21-6247-9808 (P.-M.Y.).

Received: 26 May 2014; in revised form: 25 August 2014 / Accepted: 3 September 2014 /

Published: 15 September 2014

\begin{abstract}
This study describes the extraction, preliminary characterization and evaluation of the in vitro antitumor and antioxidant activities of polysaccharides extracted from Mentha piperita (MPP). The optimal parameters for the extraction of MPP were obtained by Box-Behnken experimental design and response surface methodology (RSM) at the ratio of water to raw material of 20 , extraction time of $1.5 \mathrm{~h}$ and extraction temperature at $80{ }^{\circ} \mathrm{C}$. Chemical composition analysis showed that MPP was mainly composed of glucuronic acid, galacturonic acid, glucose, galactose and arabinose, and the molecular weight of its two major fractions were estimated to be about 2.843 and $1.139 \mathrm{kDa}$, respectively. In vitro bioactivity experiments showed that MPP not only inhibited the growth of A549 cells but possessed potent inhibitory action against DNA topoisomerase I (topo I), and an appreciative antioxidant action as well. These results indicate that MPP may be useful for developing safe natural health products.
\end{abstract}


Keywords: Mentha piperita; response surface methodology; polysaccharide; antitumor; antioxidant

\section{Introduction}

Cancer is a leading cause of death worldwide and a diverse group of diseases characterized by the uncontrolled proliferation of anaplastic cells, leading to invasion of surrounding tissues and metastasis to other organs [1]. It is one of the most lethal diseases severely threatening to human life. Chemotherapy is one of the most frequently used therapeutic modalities for the treatment of cancer, but the therapeutic outcome is usually unsatisfactory due to serious and intolerable adverse side effects. Therefore, it is very important to develop novel antitumor substances with little toxicity to the host. In recent decades, numerous polysaccharides isolated from natural materials have been proven to have few adverse effects and possess a wide range of biological functions such as antitumor and antioxidant properties [2-5]. Natural polysaccharides may prove to be important potential pharmaceuticals for the prevention and treatment of cancer in the future.

Mentha piperita L., belonging to the family Lamiaceae, is a perennial herb native to Europe, sparingly naturalized in the northern USA and Canada, and cultivated in many parts of the world. It used to be known as a hybrid of M. spicata L. (spearmint) and M. aquatic (water mint) [6]. It is best known for its fragrance and flavor compositions. In Eastern and Western traditional medicines, peppermint and its oil have been used in antispasmodics, aromatics, antiseptics or even medications for the treatment of colds, cramps, indigestions, nausea, sore throat, toothache or even cancer [7]. Modern pharmacology research has demonstrated that $M$. piperita possesses antioxidant, antitumor, antiallergenic, antiviral and antibacterial activities [8-12]. So far, research on M. piperita has focused on peppermint oil and small molecules, and there is no published information about the biological and physiochemical properties of the polysaccharides extracted from M. piperita.

Polysaccharides are polymeric carbohydrate structures, formed of repeating units joined together by glycosidic bonds. Aqueous extraction is the most common method of extraction of plant polysaccharides, and the extraction process is usually optimized by mathematics. Response surface methodology (RSM) is an empirical statistical technique for multiple regression analysis by using quantitative data obtained from properly designed experiments to solve multivariate equations simultaneously. This methodology consists of a group of mathematical and statistical procedures that can be used to evaluate the functional form of a process, involving one or more dependent variables influenced by various factors or independent variables. This methodology has been widely used to optimize the polysaccharides extraction process [13-16]. Knowing that RSM can simplify the complexity of experimental trials needed to evaluate multiple variables and their interactions, the objective of this study was to optimize the extraction process of polysaccharides from M. piperita using RSM, and to investigate their antitumor and antioxidant activities in vitro. 


\section{Results and Discussion}

\subsection{Statistical Analysis and Model Fitting}

On the basis of preliminary experiments (data not shown), the three parameters: ratio of water to raw material $(A)$, extraction time $(B)$ and extraction temperature $(C)$ were selected as the variables to optimize the extraction conditions of polysaccharide from M. Piperita (MPP). A 17-run Box-Behnken design (BBD) was applied statistically to optimize $Y$ (MPP yield) under different experimental combinations and is presented in Table 1. There was a considerable variation of $Y$ depending on the different extraction conditions. MPP yields ranged from $5.140 \%$ to $8.452 \%$.

Table 1. Box-Behnken Design (BBD) experimental design with the independent variables.

\begin{tabular}{ccccc}
\hline Run & $\boldsymbol{A}$ & $\boldsymbol{B}(\mathbf{h})$ & $\boldsymbol{C}\left({ }^{\circ} \mathbf{C}\right)$ & $\boldsymbol{Y}$ MPP Yield (\%) \\
\hline 1 & 15 & 1.0 & 80 & 5.140 \\
2 & 25 & 1.0 & 80 & 7.376 \\
3 & 15 & 2.0 & 80 & 5.769 \\
4 & 25 & 2.0 & 80 & 6.588 \\
5 & 15 & 1.5 & 70 & 5.592 \\
6 & 25 & 1.5 & 70 & 7.162 \\
7 & 15 & 1.5 & 90 & 5.838 \\
8 & 25 & 1.5 & 90 & 7.463 \\
9 & 20 & 1.0 & 70 & 7.486 \\
10 & 20 & 2.0 & 70 & 7.058 \\
11 & 20 & 1.0 & 90 & 7.152 \\
12 & 20 & 2.0 & 90 & 7.324 \\
13 & 20 & 1.5 & 80 & 7.989 \\
14 & 20 & 1.5 & 80 & 8.452 \\
15 & 20 & 1.5 & 80 & 8.328 \\
16 & 20 & 1.5 & 80 & 8.021 \\
17 & 20 & 1.5 & 80 & 8.371 \\
\hline
\end{tabular}

Using multiple regression analysis on the experimental data, the response variable and the test variables were related by the following second-order polynomial equation:

$$
\begin{gathered}
Y=82.32+7.81 A-0.52 B+0.60 C-3.54 A B+0.14 A C \\
+1.50 B C-13.78 A^{2}-6.36 B^{2}-3.41 C^{2}
\end{gathered}
$$

The coefficient of determination $\left(R^{2}=0.9862\right)$, the adjusted coefficient of determination $\left(R^{2}\right.$ Adj $\left.=0.9684\right)$ and the coefficient of variation $(\mathrm{C} . \mathrm{V} .=2.55 \%)$ are shown in Table 2 , where the values indicate that the accuracy and the general availability of the polynomial model are adequate, and the $R^{2}$ Pred of 0.9345 is in reasonable agreement with the $R^{2}$ Adj. The "Adequate Precision" of 22.21 indicated that this model could be used to navigate the design space.

The significance of each coefficient was checked using the $F$-test and the $p$-value (Table 2). The Model $F$-value of 55.48 implied that the model was significant, and there was only a $0.01 \%$ chance that a "Model $F$-value" that was this large occurred because of noise. The "Lack of Fit $F$-value" of 0.38 implied that the Lack of Fit was not significant relative to the pure error, and there was 
a $22.27 \%$ chance that a "Lack of Fit $F$-value" of such a size could have occurred because of noise. As shown in Table 2, the linear coefficients $(A)$, a quadratic term coefficient $\left(A^{2}, B^{2}, C^{2}\right)$ and cross product coefficients $(A B)$ were significant, with very small $p$-values $(p<0.05)$. The other term coefficients were not significant ( $p>0.05$ ). Therefore, $A, A^{2}, B^{2}, C^{2}$ and $A B$ were important factors in the extraction process of the polysaccharides.

Table 2. Analysis of variance (ANOVA) of the experimental results of the BBD.

\begin{tabular}{|c|c|c|c|c|c|}
\hline Source & Sum of Squares & Degree of Freedom & Mean Square & $F$-Value & $p$-Value \\
\hline Model & 16.51 & 9 & 1.83 & 55.48 & $<0.0001$ \\
\hline$A$ & 4.88 & 1 & 4.88 & 147.70 & $<0.0001$ \\
\hline$B$ & 0.022 & 1 & 0.022 & 0.65 & 0.4462 \\
\hline$C$ & 0.029 & 1 & 0.029 & 0.87 & 0.3826 \\
\hline$A B$ & 0.50 & 1 & 0.50 & 15.18 & 0.0059 \\
\hline$A C$ & $7.563 \times 10^{-4}$ & 1 & $7.563 \times 10^{-4}$ & 0.023 & 0.8840 \\
\hline$B C$ & 0.090 & 1 & 0.09 & 2.72 & 0.1492 \\
\hline$A^{2}$ & 7.99 & 1 & 7.99 & 241.71 & $<0.0001$ \\
\hline$B^{2}$ & 1.71 & 1 & 1.71 & 51.58 & 0.0002 \\
\hline$C^{2}$ & 0.49 & 1 & 0.49 & 14.80 & 0.0063 \\
\hline Residual & 0.23 & 7 & 0.033 & - & - \\
\hline Lack of Fit & 0.051 & 3 & 0.017 & 0.38 & 0.7761 \\
\hline Pure Error & 0.18 & 4 & 0.045 & - & - \\
\hline Cor Total & 16.74 & 16 & - & - & - \\
\hline $\begin{array}{l}\text { Standard } \\
\text { Deviation }\end{array}$ & C.V.\% & Press & $R^{2}$ & $R_{\text {Pred }}^{2}$ & $\begin{array}{l}\text { Adequate } \\
\text { precision }\end{array}$ \\
\hline 0.18 & 2.55 & 1.10 & 0.9862 & 0.9345 & 22.21 \\
\hline
\end{tabular}

\subsection{Analysis of Response Surface}

The relationship between independent and dependent variables was illustrated in $3 \mathrm{D}$ response surfaces and 2D contour plots generated by the model for yield of polysaccharides, and two variables were depicted in one tri-dimensional surface plot while the other variable remained at zero level. Figure 1a,b show that the effect of the ratio of water to raw material $(A)$, extraction time $(B)$ and their reciprocal interaction on polysaccharide yield, when the extraction temperature $(C)$ was fixed at zero level. $A$ and $B$ were shown to have a quadratic effect on the yield. When $A$ was kept at a lower level, the yield increased first and then decreased with the increase of $B$, and the mutual interaction between $A$ and $B$ was significant. Likewise, Figure $1 \mathrm{c}, \mathrm{d}$ show that the ratio of water to raw material $(A)$ and extraction temperature $(C)$ had a quadratic effect on the yield when extraction time $(B)$ was fixed at $1.5 \mathrm{~h}$. As shown in Figure 1e,f, when the ratio of water to raw material $(A)$ was fixed at 20, the polysaccharide yield was insignificant with increase of the extraction time $(B)$. The extraction temperature $(C)$ was shown to have a quadratic effect on the response. 
Figure 1. Contour plots (a,c,e) and response surface plots $(\mathbf{b}, \mathbf{d}, \mathbf{f})$ showing effect of ratio of water to raw material $(A)$, extraction time $(B)$ and extraction temperature $(C)$ on the yield of polysaccharide from Mentha piperita (MPP).

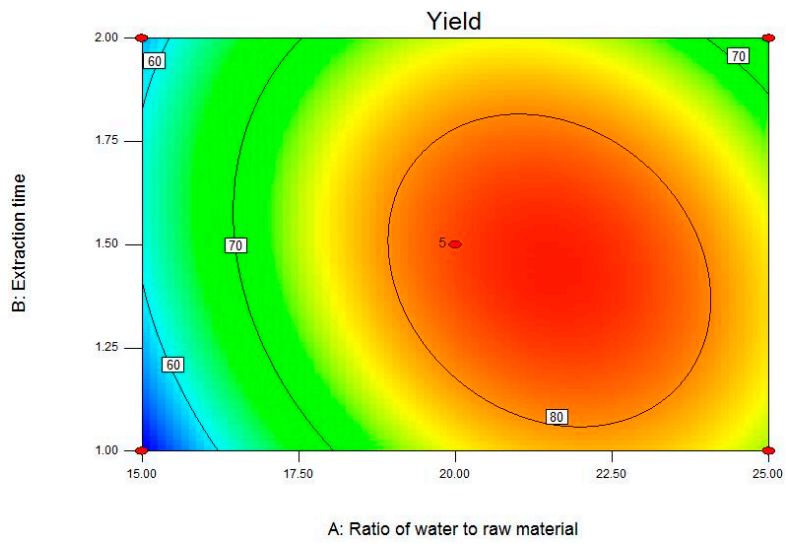

(a)

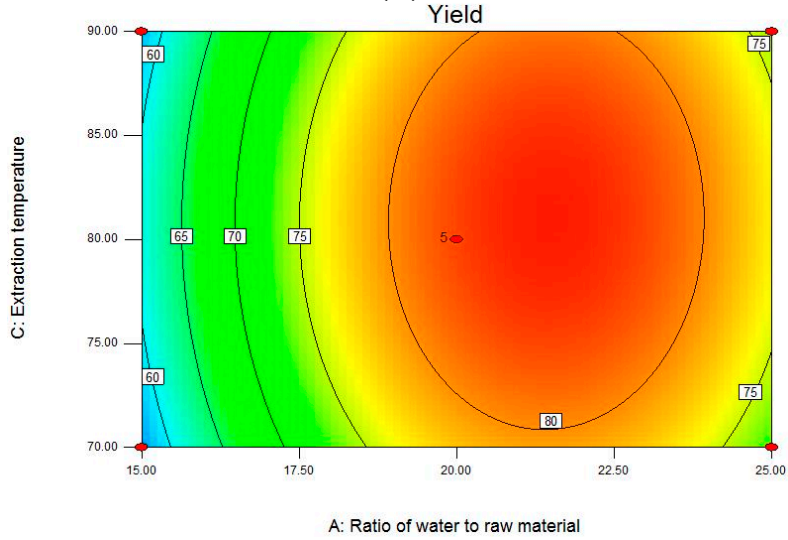

(c)

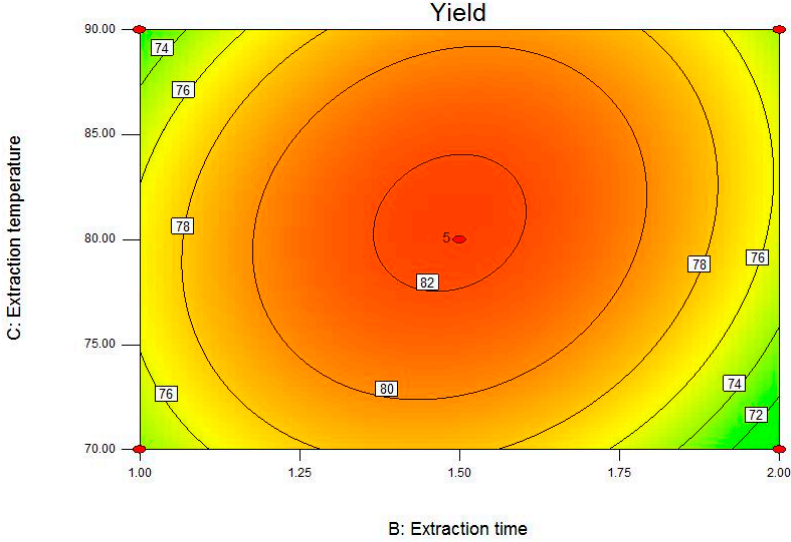

(e)

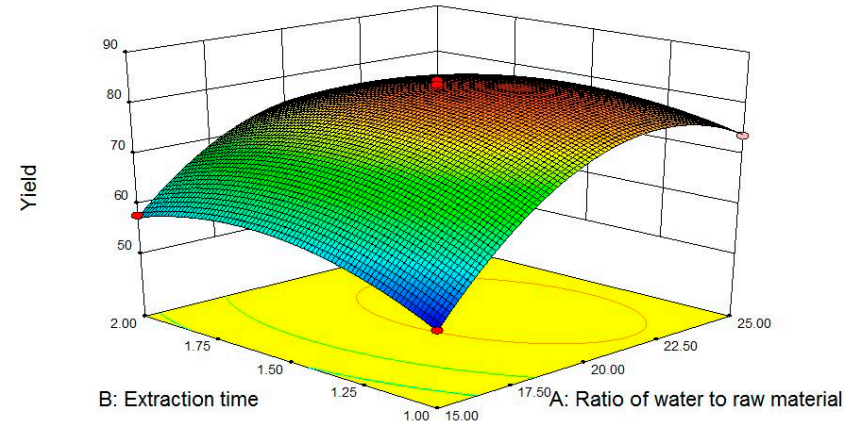

(b)

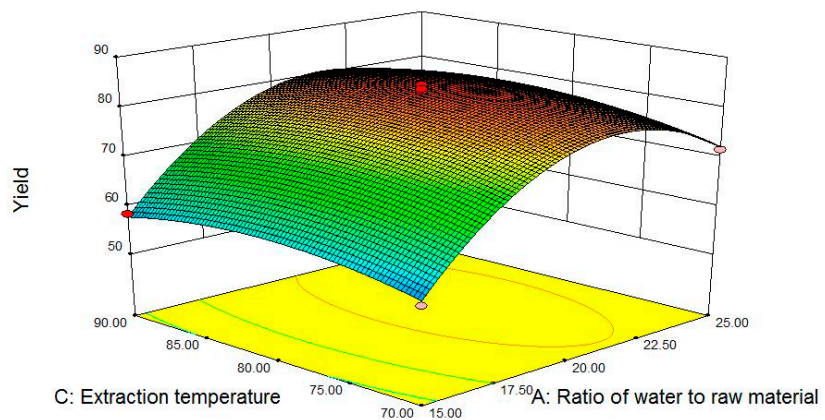

(d)

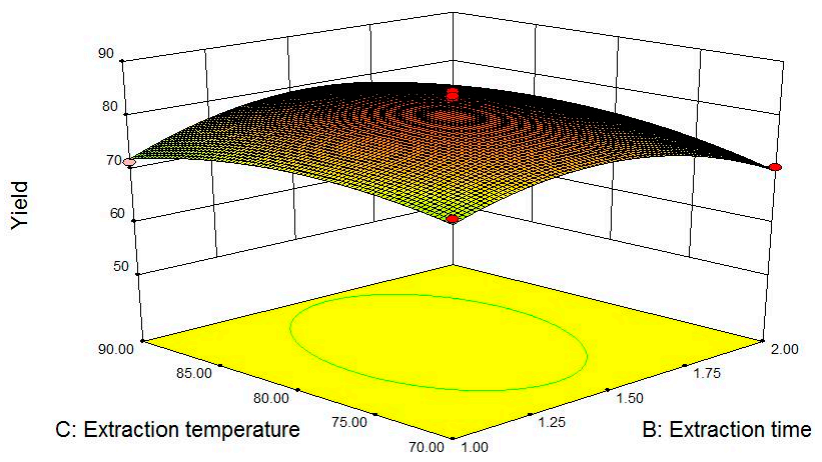

(f)

Analysis of the plots showed that the optimal conditions for MPP extraction were the ratio of water to raw material at 21.49 , the extraction time of $1.44 \mathrm{~h}$, and the extraction temperature at $80.69{ }^{\circ} \mathrm{C}$. Under these optimal conditions, the maximum predicted yield to MPP was $8.354 \%$, and the experimental yield was $8.281 \% \pm 0.387 \%$, which agreed with the predicted value. In view of practicality of operation, the extraction process is better when the ratio of water to material is at 20, an extraction time of $1.5 \mathrm{~h}$ and an extraction temperature at $80^{\circ} \mathrm{C}$, respectively. Therefore, the results indicated the suitability of the model employed and the success of RSM in optimizing the extraction conditions for MPP. 


\subsection{Physicochemical Properties of MPP (Mentha piperita)}

The chemical composition analysis indicated that the obtained MPP contained $70.48 \% \pm 1.75 \%$ sugar, $14.70 \% \pm 0.48 \%$ protein, $3.89 \% \pm 0.16 \%$ sulfate and $8.96 \% \pm 1.33 \%$ uronic acid. Moreover, MPP was heterogeneous and contained two major fractions, the molecular weight of which was estimated to be about 2.843 and $1.139 \mathrm{kDa}$, respectively (Figure 2A). The results of the monosaccharide composition analysis of MPP are shown in Figure 2B,C. HPLC (high performance liquid chromatography) analysis showed that MPP mainly consisted of glucuronic acid, galacturonic acid, glucose, galactose and arabinose.

FT-IR (Fourier Transform Infrared) spectroscopy is a powerful tool for identification of characteristic organic groups in the polysaccharides. As shown in Figure 3, there are two characteristic absorptions bands of polysaccharides: a strong and wide absorption band at about $3399 \mathrm{~cm}^{-1}$ for O-H stretching vibration, and a band in the region of $2924 \mathrm{~cm}^{-1}$ for $\mathrm{C}-\mathrm{H}$ stretching vibration. The band at about $1073 \mathrm{~cm}^{-1}$ was assigned to the valent vibrations of the $\mathrm{C}-\mathrm{O}-\mathrm{C}$ bond and glycosidic bridge. The characteristic absorptions at 874 and $832 \mathrm{~cm}^{-1}$ indicate that $\alpha$ - and $\beta$-configurations of the sugar units might simultaneously exist in MPP. These results provide valuable information for further structural study on MPP.

Figure 2. High performance gel permeation chromatography (HPGPC) chromatogram of MPP on TSKgel G3000 PWxL column (Tosoh Corporation, Yamaguchi, Japan) (A); Reversed-phase high performance liquid chromatography (HPLC) analysis of monosaccharide composition in MPP. The standards were separated under the conditions described in (B); and the derivatives of MPP hydrolysate were separated described in (C) (Man, mannose; GlcN, glucosamine; GlcA, glucuronic acid; Rha, rhamnose; GalA, galacturonic acid; Glc, glucose; Gal, galactose; Xyl, xylose; Arab, arabinose; Fuc, fucose).

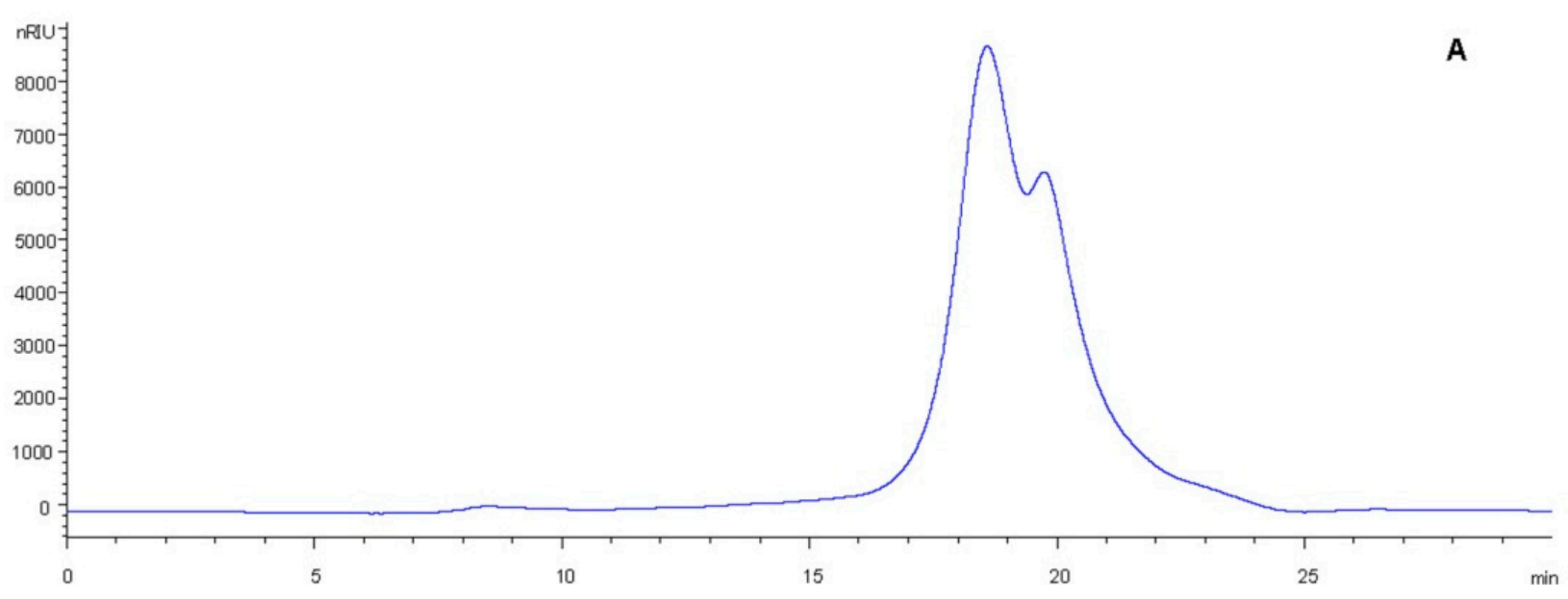


Figure 2. Cont.
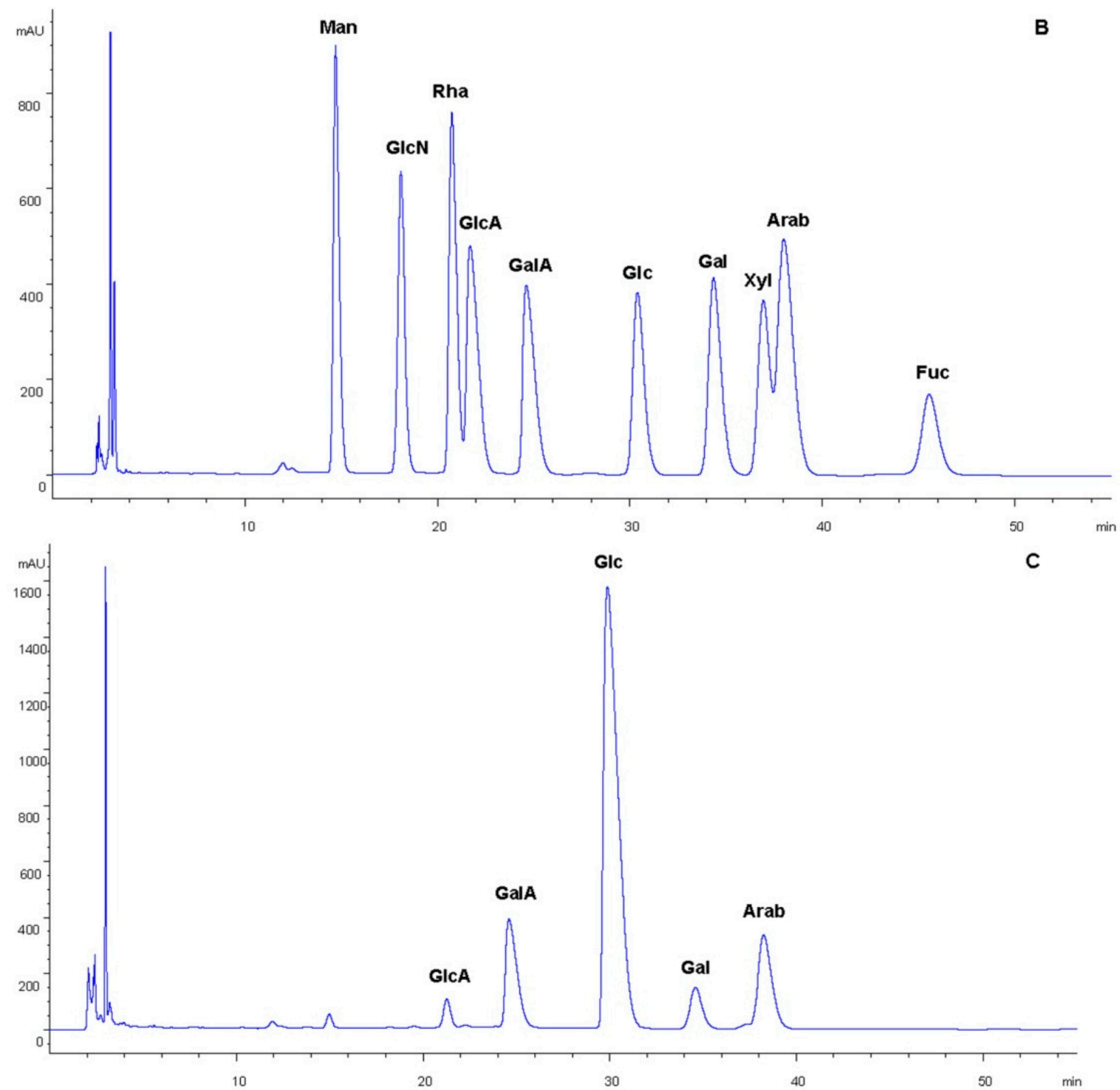

Figure 3. Fourier Transform Infrared (FT-IR) spectroscopy of MPP.

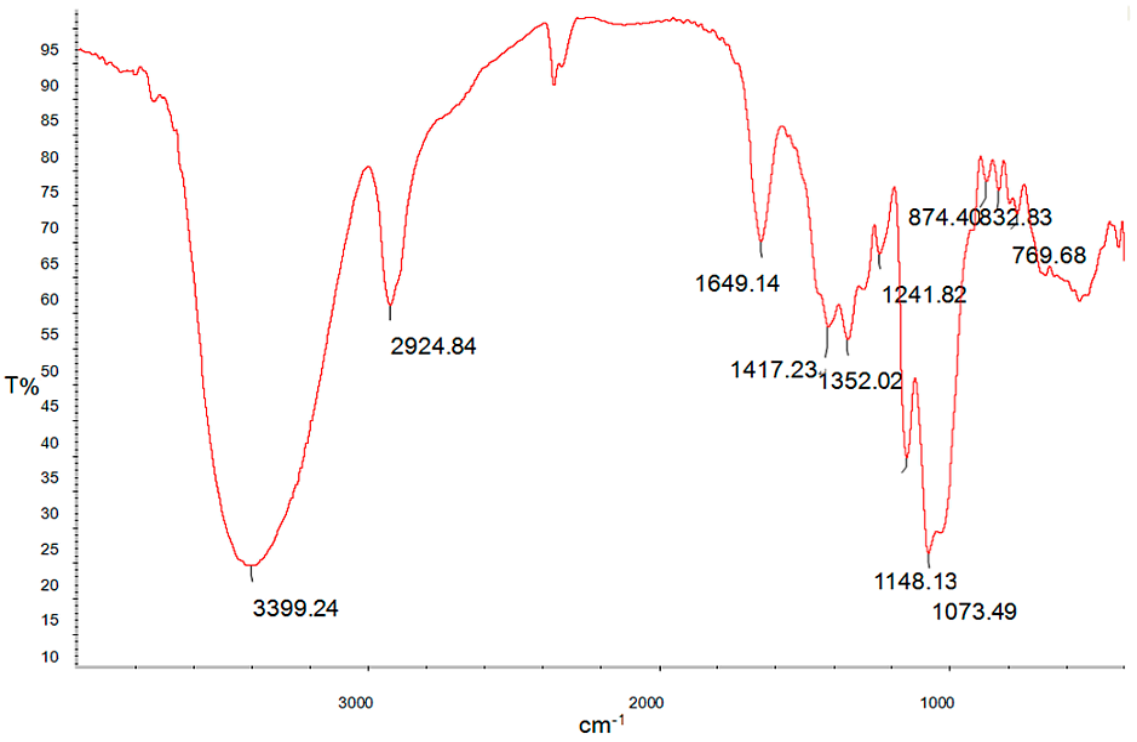




\subsection{Antitumor Activity in Vitro}

\subsubsection{In Vitro Cancer Cell Line Cytotoxicity Assay}

To explore the biological activity of MPP, the inhibitory effect on A549 non-small cell lung adenocarcinoma cells was investigated using 3-(4,5-dimethylthiazol-2-yl)-2,5-diphenyltetrazolium bromide (MTT) method (Figure 4A). The results showed that MPP had a moderate toxic effect on A549 cell line, with $\mathrm{IC}_{50}$ value of $879.52 \pm 22.55 \mu \mathrm{g} / \mathrm{mL}$. The growth of A549 cells was inhibited by MPP in a dose-dependent manner. The inhibitory rate was $54.54 \% \pm 1.38 \%$ at the highest concentration tested $(1 \mathrm{mg} / \mathrm{mL})$.

Figure 4. Antitumor activity of MPP, (A) Inhibitory effect of MPP on A549 cell lines; (B) Effect of MPP on the relaxation activity of topoisomerase I (Topo I). Lane 1, DNA alone (no topo I and no MPP); Lane 2, camptothecin (CPT) at concentration of $50 \mu \mathrm{g} / \mathrm{mL}+$ DNA + topo I; Lane 3-7, MPP at concentrations of 25, 50, 100, 200 and $400 \mu \mathrm{g} / \mathrm{mL}+$ DNA + topo I, respectively; Lane 8, topo I + DNA; Lane 9, DNA + $200 \mu \mathrm{g} / \mathrm{mL}$ MPP.

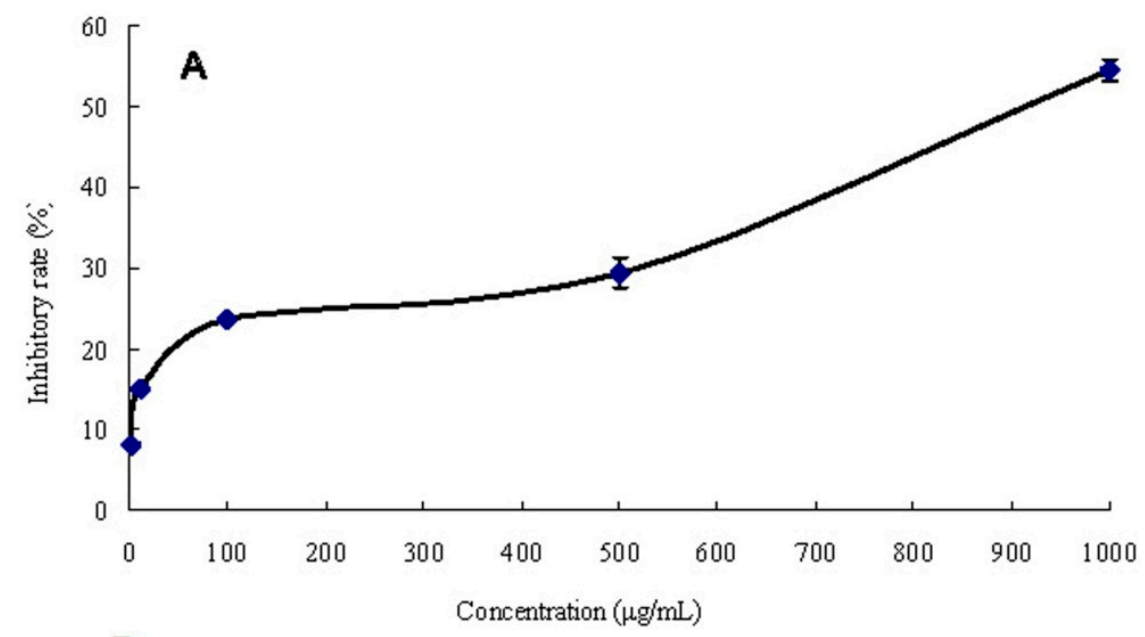

B

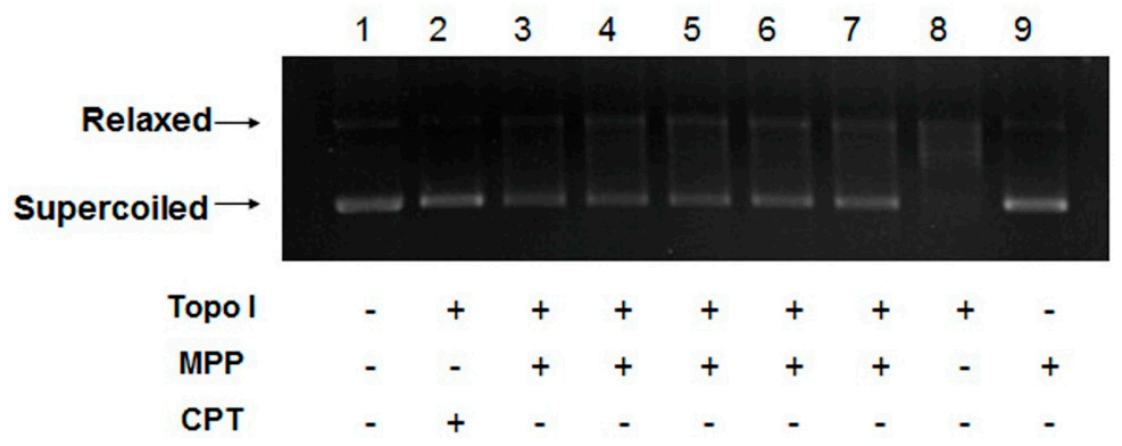

\subsubsection{DNA Topoisomerase I Inhibitory Activity}

The inhibitory activity of MPP against topo I was evaluated by agarose-gel electrophoresis. As shown in Figure 4B, lane 1 is DNA alone; lane 8 is topo I together with DNA, and supercoiled DNA was relaxed by topo I completely; in lane 9, the system consisted of DNA and $200 \mu \mathrm{g} / \mathrm{mL} \mathrm{MPP}$. Lane 1 was similar to lane 9, indicating that MPP could not combine with DNA. In lanes 3-7, MPP, DNA and topo I existed in the same system. The results showed that MPP was the inhibitor of topo I 
that can inhibit the relaxation activity of topo I toward DNA, with IC50 value of $340.81 \mu \mathrm{g} / \mathrm{mL}$. It was also found that the inhibitory activity of MPP weakened gradually with decreasing concentration.

DNA topo I is the ubiquitous enzyme that can regulate DNA topological structures by sequential breakage and reunion of DNA single strand. It was reported to be involved in DNA transcription, replication and recombination [17]. DNA topo I inhibitory effect has become an important target for cancer treatment, and some inhibitors against DNA topo I have been used in clinical treatment. Although many natural polysaccharides are proposed to have antitumor activities, few studies have reported polysaccharides that can inhibit DNA topo I activity. Japanese researchers reported a polysaccharide derived from marine microalgae that possessed notable topo I inhibitory activity, and their finding may promote further study on MPP [18]. According to the previous study, polysaccharides with high molecular weight could hardly be incorporated into the nucleus and directly inhibit topo I, and therefore it is reasonable to assume that the low molecular weight polysaccharides existing in MPP might be the active substances [18]. Further investigation is necessary to investigate the structure and action mechanism of MPP.

\subsection{In Vitro Antioxidant Activities of MPP}

\subsubsection{DPPH (1,1-Diphenyl-2-picryl-hydrazyl0) Radical Scavenging Assay}

DPPH (1,1-Diphenyl-2-picryl-hydrazyl) is a stable free radical and has been widely accepted as a method for evaluating free radical scavenging activities of antioxidants [19]. MPP clearly displayed scavenging activity against DPPH in a concentration-dependent manner (Figure 5A). The effect of MPP on scavenging DPPH was $15.43 \%$ at $0.4 \mathrm{mg} / \mathrm{mL}$, and the scavenging rate increased to $84.48 \%$ at $2 \mathrm{mg} / \mathrm{mL}$. The scavenging ability of MPP $\left(\mathrm{IC}_{50}=1.13 \mathrm{mg} / \mathrm{mL}\right)$ was similar to that of butylated hydroxytoluene (BHT) $\left(\mathrm{IC}_{50}=0.71 \mathrm{mg} / \mathrm{mL}\right)$, suggesting that MPP could be used as a free radical inhibitor and primary antioxidant.

Figure 5. Antioxidant activities of MPP, (A) scavenging of 1,1-diphenyl-2-picryl-hydrazyl (DPPH) radical; (B) scavenging of hydroxyl radical; (C) scavenging of superoxide radical; (D) reducing power and (E) total antioxidant activity. Values are representative of three separate experiments.
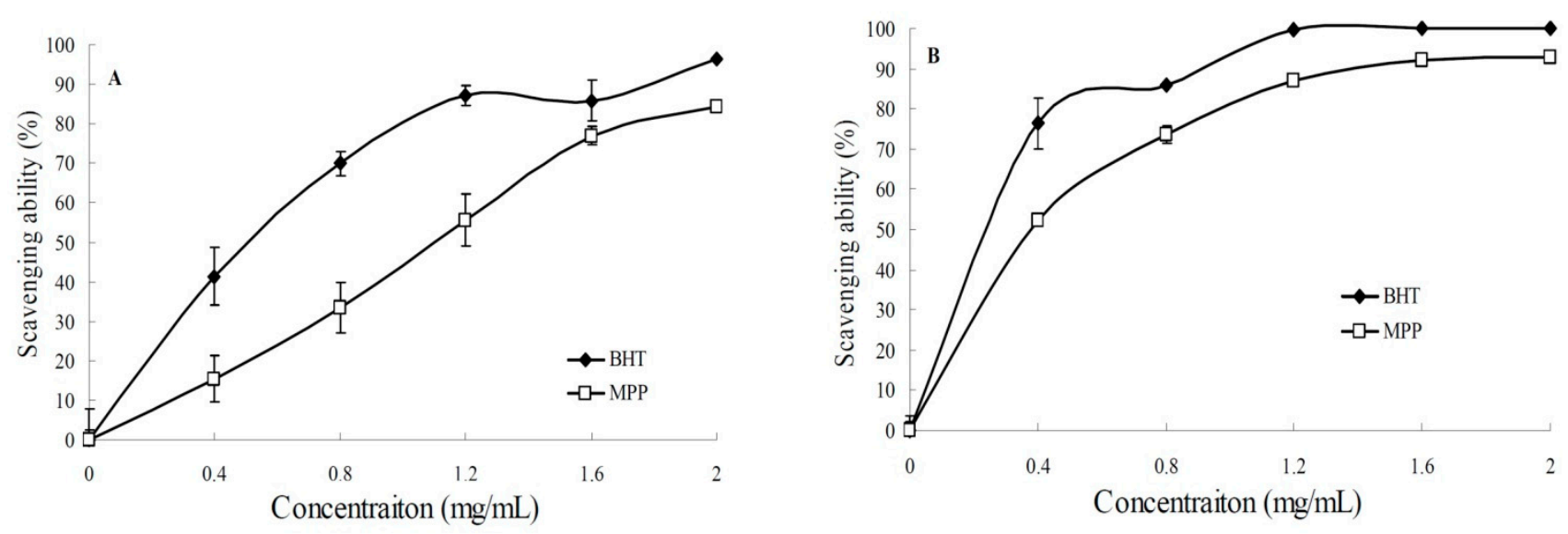
Figure 5. Cont.
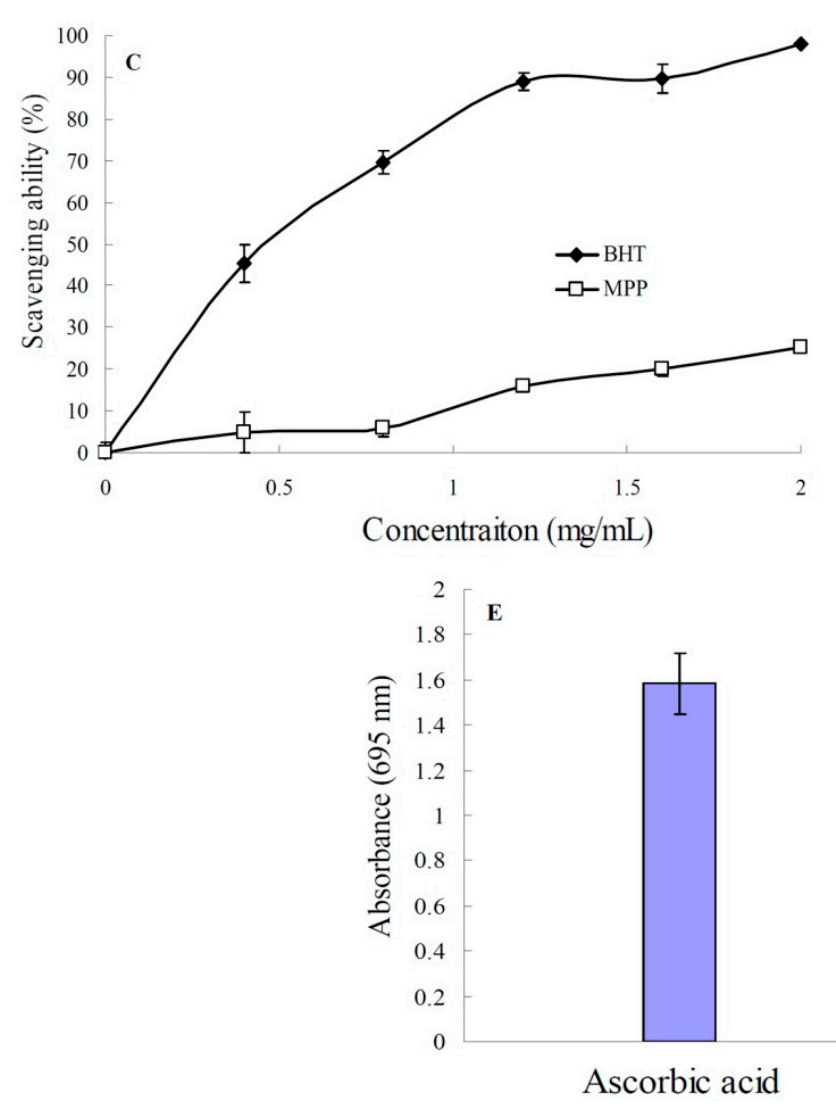

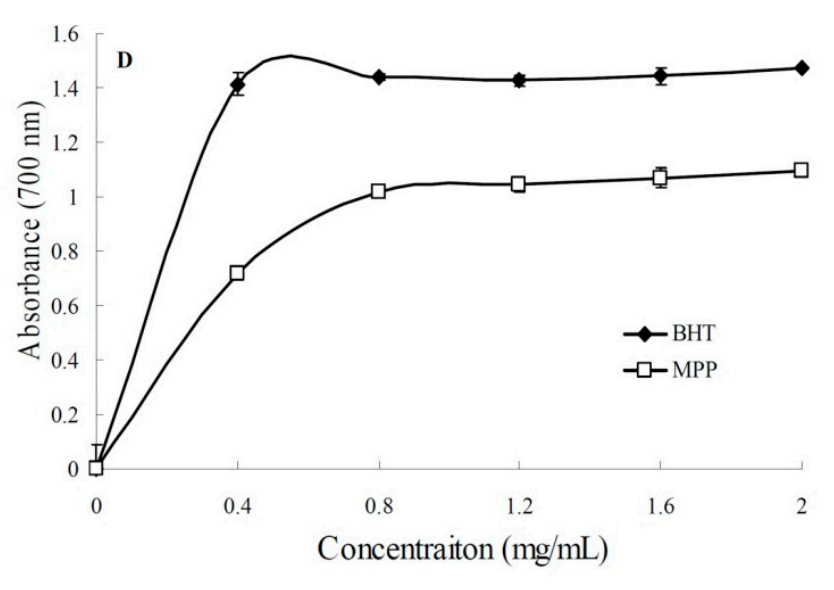

\subsubsection{Hydroxyl Radical Scavenging Activity}

Among the oxygen radicals, hydroxyl radical is the most reactive and can induce severe damage to adjacent biomolecules [19]. As shown in Figure 5B, both MPP and BHT exhibited hydroxyl radical scavenging activity. Within the concentration range of $0.4-2.0 \mathrm{mg} / \mathrm{mL}$, the hydroxyl radical scavenging ability of MPP increased firstly with increasing concentration, and then became gradually inconspicuous when the concentration was beyond $1.2 \mathrm{mg} / \mathrm{mL}$, indicating that MPP has good hydroxyl scavenging activity and can thus be used as a good hydroxyl radical scavenger.

\subsubsection{Superoxide Radical Scavenging Activity}

Superoxide radical is a reduced form of molecular oxygen created by receiving one electron from mitochondrial electron transport systems. The superoxide radical plays an important role in formation of hydrogen peroxide, hydroxyl radical, or singlet oxygen, which induces oxidative damage in lipids, proteins and DNA. It is a highly toxic species generated by numerous biological and photochemical reactions [4]. The scavenging effect of MPP on superoxide radical is shown in Figure 5C. The superoxide scavenging rate increased from $4.78 \%-25.17 \%$, when the concentration increased from $0.4-2.0 \mathrm{mg} / \mathrm{mL}$, showing a concentration-dependent manner. Although the scavenging ability of MPP increased with increase of the concentration, its scavenging ability was lower than that of BHT, indicating that MPP had weak superoxide radical scavenging ability. 


\subsubsection{Reducing Power}

The reduction of $\mathrm{Fe}$ ions is often used as an indicator of electron-donating activity. Figure 5D showed that the reducing power of MPP increased to a certain extant and then leveled off within the concentration range of $0.4-2.0 \mathrm{mg} / \mathrm{mL}$. Although the reducing power of MPP was lower than that of BHT, it still reached 1.02 at the concentration of $0.8 \mathrm{mg} / \mathrm{mL}$, indicating that MPP has a moderate reducing power. The result suggests that MPP may function as a good electron and hydrogen donor, and therefore should be able to terminate radical chain reactions by converting free radicals to more stable products.

\subsubsection{Total Antioxidant Activity}

Total antioxidant activity assay is based on the reduction of Mo (VI) to Mo (V) and subsequent formation of a green phosphate/Mo (V) complex in acid medium. As shown in Figure 5E, total antioxidant capacity of MPP was expressed as the number of equivalents of ascorbic acid. MPP exhibited effective antioxidant activity, which is equivalent to $60 \%$ of the antioxidant activity of ascorbic acid.

It is common knowledge that oxidation is imperative to many organisms for energy production. However, uncontrolled production of oxygen-derived free radicals can damage cellular components such as lipids and DNA, which may bring about diseases such as cancer, rheumatoid arthritis and atherosclerosis [20]. It has been reported that natural polysaccharides from plants possess antioxidant activities. The in vitro antioxidant activity test of the present study showed that MPP had rational DPPH, hydroxyl and superoxide radical scavenging activities, a moderate reducing power and total antioxidant activity. According to previous studies, antioxidant activity of polysaccharide depends on several structural parameters such as the degree of sulfation, the molecular weight, the sulfation position, type of monosaccharide and glycosidic branching [21]. In this study, MPP possessed low molecular weight and high content of glucose, and this special characterization and composition might be propitious to the formation of hydrogen bonds and enhance the hydrogen atom donating ability of MPP to scavenge free radicals, which might improve its antioxidant activity. On the other hand, the level of anti-oxidation and reactive oxygen species correlates well with the generation and malignant transformation of cancer cells. If substances can enhance the level of anti-oxidation and clear the reactive oxygen species in cancer cells, they may inhibit cell growth [2]. This suggests that MPP has antioxidant activity and can protect the organs against damage from free radicals, or retard the progression of disease. Therefore, the antitumor activity of MPP might be attributed to its potential antioxidant activity.

An efficient extraction process was employed to extract MPP from M. piperita and the corresponding extraction parameters were optimized by RSM. Although MPP has a high sugar content, it is still a mixture including protein, uronic acid and other impurities. These components might partially affect the antitumor and antioxidant activities of MPP. Meanwhile, molecular weight distribution analysis also showed that MPP was heterogeneous and contained two major fractions, and the relationship between its structural characteristics and biological activities is unknown. Therefore, it is necessary to carry out further studies on the precise chemical structures and biological function mechanism of MPP. 


\section{Experimental Section}

\subsection{Experiment Materials and Chemicals}

Stems and leaves of M. piperita were collected from the Experimental Halophytes Growing Base of Shandong Academic of Sciences (Jinan, China) in August 2012, dried at room temperature and ground into powder. After passing through a 10 mesh sieve, the powder was stored in the refrigerator. Fetal bovine serum (FBS) and RPMI1640 medium were purchased from Gibco Industries (Grand Island, NY, USA). A549 non-small cell lung adenocarcinoma cell line was purchased from Shanghai Institute of Cell Biology, Chinese Academy of Sciences (Shanghai, China). Topoisomerase I (calf thymus), buffer, bovine serum albumin (BSA), loading buffer and supercoiled pBR322 DNA were all from TaKaRa Biotechnology Co., Ltd. (Dalian, China). Butylated hydroxytoluene (BHT), 3-(4,5-dimethylthiazol-2-yl)-2,5-diphenyltetrazolium bromide (MTT), camptothecin (CPT), 1,1-diphenyl-2-picryl-hydrazyl (DPPH), standard monosaccharides and ascorbic acid were obtained from Sigma-Aldrich (St. Louis, MO, USA). Dextran T-series standards ( $M_{\mathrm{w}}$ (molecular weight): 180, 2500, 4600, 7100, 10,000, 21,100 and 47,100 Da) were from the National Institute for Drugs and Biological Products (Beijing, China). Other reagents used in this study were of the highest quality available from commercial vendors.

\subsection{Preparation of Polysaccharides}

Dried M. piperita stems and leaves $(1000.0 \mathrm{~g})$ were ground in a rotary mill and sieved (10 mesh) to obtain a fine powder as pretreated samples. They were then extracted with $90 \%$ ethanol at $80{ }^{\circ} \mathrm{C}$ for $2 \mathrm{~h} \times 3$ to defat and remove colored materials and fat-soluble small molecule materials. The pretreated dried samples were extracted with distilled water, with the temperature of water bath kept at a constant temperature within $\pm 1.0^{\circ} \mathrm{C}$, and an electric mixing paddle was used for a given time during the entire extraction process. The extracted slurry was centrifuged at $4000 \times g$ for $10 \min$ to collect the supernatant, and the insoluble residue was treated once again as mentioned above.

The supernatant was incorporated and concentrated to one-fifth of the initial volume using a rotary evaporator (RE-52 99, Yarong Technology and Science Inc., Shanghai, China) at $60{ }^{\circ} \mathrm{C}$ under vacuum. The resulting solution was mixed with four volumes of dehydrated ethanol (ethanol final concentration, $80 \%$ ) and kept at $4{ }^{\circ} \mathrm{C}$ overnight. Then the solution was centrifuged at $4000 \times \mathrm{g}$ for $15 \mathrm{~min}$, washed three times with dehydrated ethanol and dried under reduced pressure. The crude polysaccharides obtained, named MPP, was weighed with a balance (BS2202, SARTOUIS, Göttingen, Germany), and the polysaccharide extraction yield (\%) was calculated as follows: polysaccharide extraction yield $(\%, w / w)=[$ dried crude polysaccharide weight $(\mathrm{g}) /$ powder weight $(\mathrm{g})] \times 100 \%$.

\subsection{Experimental Design}

A 17-run Box-Behnken design (BBD) was applied statistically to optimize polysaccharide extraction from $M$. piperita. Knowing that the ratio of water to raw material, extraction time and extraction temperature significantly influenced the yield of polysaccharides, they were designated as $X_{1}(A), X_{2}(B)$ and $X_{3}(C)$ in Table 1, and prescribed into three levels, coded $+1,0$ and -1 for high, 
intermediate and low values, respectively. To minimize the effect of unexplained variability in the observed responses due to systematic errors, all the experiments were carried out at random. The variables were coded according to the following equation:

$$
X_{i}=\frac{x_{i}-x_{0}}{\Delta x} i=1,2,3
$$

In this equation $X_{i}$ is the coded value of the independent variable, $x_{i}$ is the actual value, $x_{0}$ is the value of $x_{i}$ at the center point, and $\Delta x$ is the step change. To predict the optimized conditions, a second-order polynomial model was fitted to correlate the relationship between the independent variables and the response (polysaccharide yield).

$$
Y=A_{0}+\sum_{i=1}^{3} A_{i} X_{i}+\sum_{i=1}^{3} A_{i i} X_{i}^{2}+\sum_{i=1}^{2} \sum_{j=i+1}^{3} A_{i j} X_{i j}
$$

where $Y$ is the dependent variable (the polysaccharide extraction yield), $A_{0}$ is an intercept, and $A_{i}, A_{i i}$ and $A_{i j}$ are the coefficients estimated by the model. $X_{i}$ and $X_{j}$ are the levels of the independent variables that represent the linear, quadratic and cross-product effects of the $X_{1}, X_{2}$ and $X_{3}$ factors on the response, respectively. The model evaluated the effect of each independent variable on the response. The experimental design was analyzed and the predicted data were calculated using the Design-Expert software (v.8.0.6.1 trail, State-East, Inc., Minneapolis, MN, USA) in order to estimate the response of the independent variables. The designed variables in coded units are given in Table 1 along with the experimental values of the response.

\subsection{Component Analysis}

The total sugar content was determined by the phenol-sulfuric acid method using glucose as the standard [22]. The protein content was measured by the method of Bradford [23]. The sulfate ester content was estimated according to previous literature [24]. The uronic acid content was determined by the carbazole-sulfuric acid method [25]. The molecular weight of MPP was determined by high performance gel permeation chromatography (HPGPC) on a HPLC system equipped with a TSKgel G3000 PWxL column calibration $\left(7.8 \mathrm{~mm} \times 30.0 \mathrm{~cm}\right.$ ) by eluting with $0.2 \mathrm{~mol} / \mathrm{L} \mathrm{Na}_{2} \mathrm{SO}_{4}$ at $0.5 \mathrm{~mL} / \mathrm{min}$ The eluate was monitored by a refractive index detector. Column calibration was performed with standard dextrans ( $M_{\mathrm{w}}$ : 180, 2500, 4600, 7100, 10,000, 21,100 and 47,100 Da). The calibration curve of $\log M \mathrm{w}$ (molecular weight) of standard dextrans against their elution time (ET) was obtained $\left(\log M_{\mathrm{W}}=-0.3151 \mathrm{ET}+9.3524, R^{2}=0.9959\right)$ [26].

Monosaccharide composition was determined by reversed-phase high performance liquid chromatography (HPLC) after pre-column derivatization and UV detection with minor modifications [26]. Five mg MPP was hydrolyzed with $2 \mathrm{~mol} / \mathrm{L}$ trifluoroacetic acid at $100{ }^{\circ} \mathrm{C}$ for $6 \mathrm{~h}$. Excessive acid was removed by co-distillation with methanol after hydrolysis. One hundred $\mathrm{mg}$ dry hydrolysate was dissolved in $100 \mu \mathrm{L} 0.3 \mathrm{~mol} / \mathrm{L} \mathrm{NaOH}$, and added to $120 \mu \mathrm{L} 0.5 \mathrm{~mol} / \mathrm{L}$ methanol solution of 1-phenyl-3-methyl-5-pyrazolone (PMP) at $70{ }^{\circ} \mathrm{C}$ for $1 \mathrm{~h}$. The mixture was added to $100 \mu \mathrm{L} 0.3 \mathrm{~mol} / \mathrm{L}$ $\mathrm{HCl}$, vigorously shaken, and then centrifuged at $2400 \times \mathrm{g}$ for $5 \mathrm{~min}$. The supernatant containing the labeled carbohydrate was filtered through $0.22 \mu \mathrm{m}$ nylon membranes (MSI, Westborough, MA, USA) and $10 \mu \mathrm{L}$ of the filtrate was injected into the $\mathrm{C}_{18}$ column (Kromasil, $4.6 \times 250 \mathrm{~mm}$, particle size $5 \mu \mathrm{m}$, 
Akzo Nobel, Sweden). The sample was analyzed by a HPLC system (Aglient 1260 Infinity HPLC, Agilent Technologies, Santa Clara, CA, USA). The mobile phase was a mixture of $0.1 \mathrm{~mol} / \mathrm{L} \mathrm{KH}_{2} \mathrm{PO}_{4}$ (pH 10) and acetonitrile (87:13). The flow rate was set at $1.0 \mathrm{~mL} / \mathrm{min}$ and column temperature was set at $30{ }^{\circ} \mathrm{C}$. Sugar identification was done by comparison with reference sugars (mannose, glucosamine, glucuronic acid, rhamnose, galacturonic acid, glucose, galactosel, xylose, arabinose and fucose).

\subsection{Fourier Transform Infrared (FT-IR) Spectroscopy of MPP}

MPP was mixed with spectroscopic grade potassium bromide $(\mathrm{KBr})$ powder, ground and pressed into 1-mm pellets for FI-IR measurement. The FI-IR spectrum of MPP was determined using the Thermo antaris 2 spectrometer in the frequency range of $4000-400 \mathrm{~cm}^{-1}$.

\subsection{Antitumor Activity in Vitro}

\subsubsection{In Vitro Cancer Cell Line Cytotoxicity Assay}

A549 non-small cell lung adenocarcinoma cell line was used to assay the antitumor activity of MPP. Cells were inoculated into 96-well plates at $1 \times 10^{4}$ cells per well. RPMI-1640 containing antibiotics $(100 \mu \mathrm{g} / \mathrm{mL}$ streptomycin and $100 \mathrm{U}$ penicillin) and $10 \%$ FBS were used as the culture medium. After $4 \mathrm{~h}$ preincubation of the cells in a humidified $5 \% \mathrm{CO}_{2}$ incubator at $37^{\circ} \mathrm{C}$, MPP was added with final concentrations of $1,10,100,500$ and $1000 \mu \mathrm{g} / \mathrm{mL}$, followed by further incubation for $24 \mathrm{~h}$. Five $\mathrm{mg} / \mathrm{mL}$ MTT solution dissolved in phosphate buffered saline (PBS) was added to each well by administering $10 \mu \mathrm{L}$ per well. The cells were cultured for another $4 \mathrm{~h}$, and then the culture medium was discarded. Finally, $100 \mu \mathrm{L}$ dimethyl sulfoxide (DMSO) was added to each well, mixed, and measured at $570 \mathrm{~nm}$.

\subsubsection{Assay of DNA Topoisomerase I (Topo I) Inhibitory Activity}

Topo I inhibitory activity was assayed by relaxation of supercoiled pBR322 DNA according to the manufacturer's instructions (Takara, Dalian, China). An amount of $0.5 \mu \mathrm{g}$ supercoiled pBR322 DNA, 1 unit of topo I and different concentrations of MPP were incubated for $30 \mathrm{~min}$ at $37^{\circ} \mathrm{C}$ in DNA Topo I buffer (10×: $350 \mathrm{mM}$ Tris-HCl pH 8.0, $720 \mathrm{mM} \mathrm{KCl,} 50 \mathrm{mM} \mathrm{MgCl} 2,50 \mathrm{mM}$ dithiothreitol (DTT), $50 \mathrm{mM}$ spermidine) with $0.01 \% \mathrm{BSA}$, in a total volume of $20 \mu \mathrm{L}$. The effect of MPP on the plasmid DNA was assayed using the above method, but only $0.5 \mu \mathrm{g}$ supercoiled pBR322 DNA and $200 \mu \mathrm{g} / \mathrm{mL}$ MPP were used for incubation at $37{ }^{\circ} \mathrm{C}$ for $30 \mathrm{~min}$ in DNA Topo I buffer to a total volume of $20 \mu \mathrm{L}$. MPP was diluted to $25,50,100,200$ and $400 \mu \mathrm{g} / \mathrm{mL}$ using $\mathrm{H}_{2} \mathrm{O}$. The reaction was terminated by addition of $2 \mu \mathrm{L} 10 \%$ sodium dodecyl sulfate (SDS) and $2 \mu \mathrm{L} 6 \times$ loading dye solution. Samples were then electrophoresed in $1 \%$ agarose gel in Tris-acetate-ethylene diamine tetraacetic acid (EDTA) buffer for $40 \mathrm{~min}$ at $100 \mathrm{~V}$. The gel was stained with Genview at room temperature and photographed with a UV transilluminator (G:Box, Syngene, Cambridge, UK). CPT was selected as reference drug. Topo I inhibitory activity was quantitated by determining the intensity of supercoiled and relaxed forms of plasmid DNA using the SynGene GeneTools imaging software. 


\subsection{Antioxidant Activity of MPP in Vitro}

\subsubsection{DPPH Radical Scavenging Assay}

The antioxidant activities of MPP were measured using the stable DPPH radical according to previous literature [26]. Briefly, $4 \mathrm{~mL} 0.004 \%$ methanol solution of DPPH was added to the sample solution at different concentrations $(0.4-2.0 \mathrm{mg} / \mathrm{mL})$. The mixture was shaken vigorously and left to stand for $30 \mathrm{~min}$ in darkness. Absorbance (A) was measured at $517 \mathrm{~nm}$. The capacity to scavenge DPPH radical was calculated using the following equation.

$$
\text { Scavenging rate } \%=\left[\left(\mathrm{A}_{\text {blank }}-\mathrm{A}_{\text {sample }}\right) / \mathrm{A}_{\text {control }} \times 100\right]
$$

where $\mathrm{A}_{\text {blank }}$ is the A of the control reaction (containing all reagents except the sample) and $\mathrm{A}_{\text {sample }}$ is the $\mathrm{A}$ in the presence of MPP. BHT was used as positive control.

\subsubsection{Hydroxyl Radical Scavenging Activity}

Hydroxyl radical scavenging activity was measured by the Smiroff method with some modification [26]. Different concentrations $(0.4,0.8,1.2,1.6$ and $2.0 \mathrm{mg} / \mathrm{mL})$ of MPP were dissolved. One $\mathrm{mL}$ of sample solution was mixed with $1.0 \mathrm{~mL} 9.0 \mathrm{mM} \mathrm{FeSO}_{4}, 1.0 \mathrm{~mL} 9.0 \mathrm{mM}$ salicylic acid and ethanol solution, $1.0 \mathrm{~mL} 0.3 \% \mathrm{H}_{2} \mathrm{O}_{2}$ and distilled water to $3 \mathrm{~mL}$ for $30 \mathrm{~min}$ at $37{ }^{\circ} \mathrm{C}$. The hydroxyl radical was detected by monitoring at $510 \mathrm{~nm}$. The hydroxyl radical scavenging effect was calculated as follows:

$$
\text { Scavenging rate } \%=\left(\mathrm{A}_{\text {blank }}-\mathrm{A}_{\text {sample }}\right) / \mathrm{A}_{\text {control }} \times 100
$$

where Ablank and $\mathrm{A}_{\text {sample }}$ represent the A of the blank control group and sample group under $510 \mathrm{~nm}$, respectively. BHT was used as positive control.

\subsubsection{Superoxide Radical Scavenging Activity}

Superoxide radical scavenging activity was determined according to the previous study [26]. Superoxide radical was generated by pyrogallic acid. MPP was dissolved in distilled water at $0.4,0.8$, $1.2,1.6$, and $2.0 \mathrm{mg} / \mathrm{mL}$. The sample solution $(1 \mathrm{~mL})$ was mixed with $2 \mathrm{~mL} 0.05 \mathrm{~mol} / \mathrm{L}$ Tris- $\mathrm{HCl}$ buffer $(\mathrm{pH} 8.2)$ and incubated at $25{ }^{\circ} \mathrm{C}$ in a water bath for $20 \mathrm{~min}$. Then pyrogallic acid $(0.4 \mathrm{~mL}$, $5 \mathrm{mmol} / \mathrm{L}$ ) was added, and the mixture was shaken rapidly at room temperature. The A value of the mixture was measured at $325 \mathrm{~nm}$ per $30 \mathrm{~s}$ against a blank. The scavenging ability to inhibit pyrogallol autoxidation was calculated using the equation:

$$
\text { Scavenging rate } \%=\left(\mathrm{S}_{\text {blank }}-\mathrm{S}_{\text {sample }}\right) / \mathrm{S}_{\text {control }} \times 100
$$

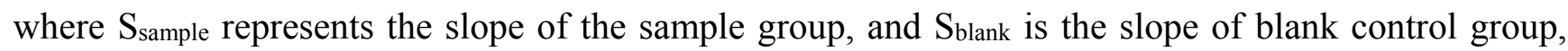
where the decrease of Ssample indicates an increase in the restraining power. BHT was used as positive control. 


\subsubsection{Reducing Power}

The reducing power was determined using the previously described method with some modifications [27]. Varying concentration $(0.4,0.8,1.2,1.6$ and $2.0 \mathrm{mg} / \mathrm{mL})$ of MPP were placed in $2.5 \mathrm{~mL} 0.2 \mathrm{~mol} / \mathrm{L}$ phosphate buffer ( $\mathrm{pH} 6.6$ ), to which $2.5 \mathrm{~mL}$ of potassium ferricyanide (1\%) was added. The mixture was incubated at $50{ }^{\circ} \mathrm{C}$ for $20 \mathrm{~min}$, followed by addition of $2.5 \mathrm{~mL}$ of trichloroacetic acid $(10 \%)$. The mixture then was centrifuged at $6000 \times \mathrm{g}$ for $10 \mathrm{~min}$. The upper layer solution $(2.5 \mathrm{~mL})$ was mixed with $2.5 \mathrm{~mL}$ water and $1 \mathrm{~mL} \mathrm{FeCl}_{3}(0.1 \%)$. Then, the A of the reaction mixture was read spectrophotometrically at $700 \mathrm{~nm}$ against a water blank. BHT was used as positive control.

\subsubsection{Total Antioxidant Activity}

The assay was based on the reduction of Mo (VI) to Mo (V) by the extract and subsequent formation of a green phosphate/Mo (V) complex at acid medium [28]. An amount of $0.3 \mathrm{~mL}$ of sample solution was combined with $3 \mathrm{~mL}$ reagent solution $(0.6 \mathrm{~mol} / \mathrm{L}$ sulfuric acid, $28 \mathrm{mmol} / \mathrm{L}$ sodium phosphate and $4 \mathrm{mmol} / \mathrm{L}$ ammonium molybdate). The tube was incubated at $95{ }^{\circ} \mathrm{C}$ for $90 \mathrm{~min}$. After cooling the mixture to room temperature, the A value of the solution was measured at $695 \mathrm{~nm}$ against a blank. The antioxidant activity is expressed as the number of equivalents of ascorbic acid.

\section{Conclusions}

In the present study, we used RSM with a BBD to optimize the MPP extraction process and investigated its chemical composition and bioactivities. The optimal experimental yield $(8.281 \% \pm 0.387 \%)$ was achieved under the following extraction conditions: the ratio of water to raw material at 21.49 , the extraction time of $1.44 \mathrm{~h}$ and the extraction temperature at $80.69^{\circ} \mathrm{C}$. Under these optimum conditions, the experimental extraction yield agreed closely with the predicted yield of $8.354 \%$. In view of the practicality of operation, the extraction process is better when the ratio of water to material is at 20 , extraction time of $1.5 \mathrm{~h}$ and extraction temperature at $80{ }^{\circ} \mathrm{C}$, respectively. MPP is mainly composed of glucuronic acid, galacturonic acid, glucose, galactose and arabinose, and the molecular weight of its major fraction was estimated to be about $23.37 \mathrm{kD}$. MPP showed appreciable antitumor activity in vitro. Its inhibitory activity against topo I might be an effective way to achieve antitumor activity. The results of our antioxidant activity assay show that MPP possesses appreciable antioxidant activity and free radical scavenging activity in vitro. This study may provide a theoretical basis for systematic research, rational development and utilization of peppermint resources.

\section{Acknowledgments}

This work is funded by the Open Research Fund Program of Key Laboratory of Marine Drugs (Ocean University of China), Ministry of Education [KLMD (OUC) 201304], and partly supported by National Natural Science Foundation of China (No. 41306133, 31240030 and 81202104), Development of new salt-tolerant plant cultivars and their integrated utilization (2011DFA30990), Excellent Middle-Aged and Youth Scientist Award Foundation of Shandong Province (BS2013HZ025 and BS2013HZ016) and the National High Technology Research and Development Program of China (863 Program) (2013AA093001). 


\section{Author Contributions}

Conceived and designed the experiments: Rui-Hong $\mathrm{Li}$ and Pei-Ming Yang. Performed the experiments: Xin Liu, Zhen-Liang Sun and Ai-Rong Jia. Analyzed the data: Ya-Ping Shi. Contributed reagents/materials/analysis tools: Zhen-Liang Sun.

\section{Conflicts of Interest}

The authors declare no conflict of interest.

\section{References}

1. Zong, A.; Cao, H.; Wang, F. Anticancer polysaccharides from natural resources: A review of recent research. Carbohydr. Polym. 2011, 90, 1395-1410.

2. Chen, X.; Nie, W.; Yu, G.; Li, Y.; Hu, Y.; Lu, J.; Jin, L. Antitumor and immunomodulatory activity of polysaccharides from Sargassum fusiforme. Food Chem. Toxicol. 2012, 50, 695-700.

3. Zhao, Q.S.; Xie, B.X.; Yan, J.; Zhao, F.C.; Xiao, J.; Yao, LY.; Zhao, B.; Huang, Y.X. In vitro antioxidant and antitumor activities of polysaccharides extracted from Asparagus officinalis. Carbohydr. Polym. 2012, 87, 392-396.

4. Jiang, C.; Wang, M.; Liu, J.; Gan, D.; Zeng, X. Extraction, preliminary characterization, antioxidant and anticancer activities in vitro of polysaccharides from Cyclina sinensis. Carbohydr. Polym. 2011, 84, 851-857.

5. Shao, P.; Chen, X.; Sun, P. In vitro antioxidant and antitumor activities of different sulfated polysaccharides isolated from three algae. Int. J. Biol. Macromol. 2013, 62, 155-161.

6. Grigoleit, H.G.; Grigoleit, P. Peppermint oil in irritable bowel syndrome. Phytomedicine 2005, 12, 601-606.

7. McKay, D.L.; Blumberg, J.B. A review of the bioactivity and potential health benefits of peppermint tea (Mentha piperita L.). Phytother. Res. 2006, 20, 619-633.

8. Zheng, W.; Wang, S.Y. Antioxidant activity and phenolic compounds in selected herbs. J. Agric. Food Chem. 2001, 49, 5165-5170.

9. Kim, S.; Cho, Y.; Park, S. Cytotoxicity of methanol extracts of edible herbs against L1210 cells with the changes of antioxidant enzymes activities (in Korean). Korean J. Pharm. 2002, 33, 376-383.

10. Inoue, T.; Sugimoto, Y.; Masuda, H.; Kamei, C. Antiallergic effect of flavonoid glycosides obtained from Mentha piperita L. Biol. Pharm. Bull. 2002, 25, 256-259.

11. Herrmann, E.C.; Kucera, L.S. Antiviral substances in plants of the mint family (Labiatae). III. Peppermint (Mentha piperita) and other mint plants. Proc. Soc. Exp. Biol. Med. 1967, 124, 874-878.

12. Andogan, B.C.; Baydar, H.; Kaya, S.; Demirci, M.; Ozbasar, D.; Mumcu, E. Antimicrobial activity and chemical composition of some essential oils. Arch. Pharm. Res. 2002, 25, 860-864.

13. Guo, X.; Zou, X.; Sun, M. Optimization of extraction process by response surface methodology and preliminary characterization of polysaccharides from Phellinus igniarius. Carbohydr. Polym. 2010, 80, 344-349.

14. Wang, Z.; Wang, C.; Guan, Y. Extraction of polysaccharides from Phellinus nigricans mycelia and their antioxidant activities in vitro. Carbohydr. Polym. 2014, 99, 110-115. 
15. Samvati, V.; Manoochehrizade, A. Polysaccharide extraction from Malva sylvestris and its anti-oxidant activity. Int. J. Biol. Macromol. 2013, 60, 427-436.

16. Li, P.; Lu, S.; Shan, T.; Mou, Y.; Li, Y.; Sun, W.; Zhou, L. Extraction optiminization of water-extracted Mycelial polysaccharide from endophytic fungus Fusarium oxysporum Dzf17 by response surface methodogy. Int. J. Mol. Sci. 2012, 13, 5441-5453.

17. Lee, C.C.; Chang, D.M.; Huang, K.F.; Chen, C.L.; Chen, T.C.; Lo, Y.; Guh, J. H.; Huang, H.S. Design, synthesis and antiproliferative evaluation of fluorenone analogs with DNA topoisomerase I inhibitory properties. Bioorg. Med. Chem. 2013, 21, 7125-7133.

18. Umemura, K.; Yanase, K.; Suzuki, M.; Okutani, K.; Yamori, T.; Andoh, T. Inhibition of DNA topoisomerases I and II, and growth inhibition of human cancer cell lines by a marine microalgal polysaccharide. Biochem. Pharmacol. 2003, 66, 481-487.

19. Balavigneswaran, C.K.; Kumar, T.; Packiaraj R.M.; Veeraraj, A.; Parkash, S. Anti-oxidant activity of polysaccharides extracted from Isocrysis galbana using RSM optimized conditions. Int. J. Biol. Macromol. 2013, 60, 100-108.

20. Wang, R.F.; Chen, P.; Jia, F.; Tang, J.; Ma, F. Optimization of polysaccharides from Panax japonicas C.A. Meyer by RSM and its anti-oxidant activity. Int. J. Biol. Macromol. 2012, 50, 331-336.

21. Shao, P.; Chen, X.; Sun, P. Chemical characterization, antioxidant and antitumor activity of sulfated polysaccharide from Sargassum horneri. Carbohydr. Polym. 2014, 105, 260-269.

22. Dubois, M.; Gilles, K.A.; Hamilton, J.K.; Rebers, P.T.; Smith, F. Colorimetric method for determination of sugars and related substances. Anal. Chem. 1956, 28, 350-356.

23. Bradford, M.M. A rapid and sensitive method for the quantitation of microgram quantities of protein utilizing the principle of protein-dye binding. Anal. Biochem. 1976, 72, 248-254.

24. Therho, T.T.; Hartiala, K. Method for determination of the sulfate content of glycosamino glycans. Anal. Biochem. 1971, 41, 471-476.

25. Bitter, T.; Muir, H.M. A modified uronic acid carbazole reaction. Anal. Biochem. 1962, 4, 330-334.

26. Liu, X.; Sun, Z.L.; Zhang, M.S.; Meng, X.M.; Xia, X.K.; Yuan, W.P.; Xue, F.; Liu, C.H. Antioxidant and antihyperlipidemic activities of polysaccharides from sea cucumber Apostichopus japonicus. Carbohydr. Polym. 2012, 90, 1664-1670.

27. Sun, H.; Mao, W.; Chen, Y.; Guo, S.; Li, H.; Qi, X.; Chen, Y.; Xu, J. Isolation, chemical characteristics and antioxidant properties of the polysaccharides from marine fungus Penicillium sp. F23-2. Carbohydr. Polym. 2009, 78, 117-124.

28. Prieto, P.; Pineda, M.; Aguilar, M. Spectrophotometric quantitation of antioxidant capacity through the formation of a phosphomolybdenum complex: specific application to the determination of Vitamin E. Anal. Biochem. 1999, 269, 337-341.

(C) 2014 by the authors; licensee MDPI, Basel, Switzerland. This article is an open access article distributed under the terms and conditions of the Creative Commons Attribution license (http://creativecommons.org/licenses/by/3.0/). 